\title{
Article
}

\section{Influence of physical properties on polymer flammability in the cone calorimeter}

Patel, Parina, Hull, T Richard, Stec, Anna A and Lyon, Richard E.

Available at http://clok.uclan.ac.uk/1915/

Patel, Parina, Hull, T Richard ORCID: 0000-0002-7970-4208, Stec, Anna A ORCID: 0000-0002-6861-0468 and Lyon, Richard E. (2011) Influence of physical properties on polymer flammability in the cone calorimeter. Polymers for Advanced Technologies, 22 (7). pp. 1100-1107. ISSN 1042-7147

It is advisable to refer to the publisher's version if you intend to cite from the work. http://dx.doi.org/10.1002/pat.1943

For more information about UCLan's research in this area go to http://www.uclan.ac.uk/researchgroups/ and search for <name of research Group>.

For information about Research generally at UCLan please go to http://www.uclan.ac.uk/research/

All outputs in CLoK are protected by Intellectual Property Rights law, including Copyright law. Copyright, IPR and Moral Rights for the works on this site are retained by the individual authors and/or other copyright owners. Terms and conditions for use of this material are defined in the policies page.

\section{CLoK}

Central Lancashire online Knowledge www.clok.uclan.ac.uk

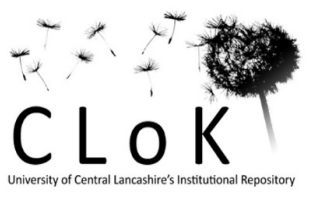




\title{
Influence of Physical Properties on Polymer Flammability in the Cone Calorimeter
}

\author{
Parina Patel ${ }^{\mathrm{a}}$, T. Richard Hull*a, Anna A. Stec ${ }^{\mathrm{a}}$ and Richard E. Lyon ${ }^{\mathrm{b}}$ \\ ${ }^{a}$ Centre for Fire and Hazards Science, School of Forensic and Investigative Science, University Of \\ Central Lancashire, Preston, PR1 2HE, UK \\ ${ }^{b}$ Fire Safety, Federal Aviation Administration, William J. Hughes Technical Centre, Atlantic City \\ International Airport, NJ 08405, USA \\ *trhull@uclan.ac.uk
}

\begin{abstract}
The relationship between physical properties and fire performance as measured in the cone calorimeter is not well understood. A number of studies have identified relationships between the physical and chemical properties of polymeric materials and their gasification behaviour which can be determined through numerical pyrolysis models. ThermaKin, a one-dimensional pyrolysis model, has recently been employed to predict the burning behaviour in fire calorimetry experiments. The range of thermal, chemical and optical properties of various polymers have been utilised to simulate the processes occurring within a polymer exposed to a uniform heat flux, such as in a cone calorimeter. ThermaKin uses these material properties to predict the mass flux history in a cone calorimeter. Multiplying the mass flux history by the heat of combustion of the fuel gases gives the HRR history and these have been calculated for cone calorimeter experiments at $50 \mathrm{~kW} \mathrm{~m}^{-2}$ incident heat flux for the lowest, average and highest values of physical parameters exhibited by common polymers. In contrast with actual experiments in fire retardancy, where several parameters change on incorporation of an additive, this study allows for the effect of each parameter to be seen in isolation. The parameters used in this study are grouped into physical properties (density, heat capacity and thermal conductivity), optical properties (absorption and reflectivity), and chemical properties (heat of decomposition, kinetic parameter and heat of combustion). The study shows how the thermal decomposition kinetic parameters effect the surface burning (pyrolysis) temperature and resulting heat release rate history, as well as the relative importance of other properties directly related to the chemical composition. It also illustrates the effect of thermal inertia (the product of density, heat capacity and thermal conductivity) and of the samples' ability to absorb radiant heat.
\end{abstract}

\section{Introduction}

As the utilisation of polymeric materials steadily embraces a wider variety of potentially hazardous applications, greater emphasis must be placed on mitigating the danger of fire. The physical characteristics of polymers and a better understanding of the behaviour of such materials when exposed to ignition sources is, therefore, a necessity. The ignitability and burning behaviour of polymers is a complex process involving interactions between a number of physical and chemical processes. Improved development of new fire safe materials would result from being able to understand the effect on burning behaviour of altering each variable independently. Unfortunately such studies are not practically feasible since any modification to the polymer, such as the incorporation of an additive, results in changes to a range of physical and chemical properties and processes. In many cases fire retardants (FRs) have chemical effects, such as intumescence, 
carbonisation, ceramicisation or stabilisation of the polymer. These effects are masked by changes in physical properties, resulting from the incorporation of FR additives, which are highlighted in this study. Where the behaviour of the processes can be reliably predicted, these can be incorporated into models of burning behaviour. Although state of the art models cannot yet make reliable predictions of time to ignition or heat release rate (HRR) history, such predictions are of great value in differentiating between expected, predictable behaviour and unexpected phenomena such as different chemical pathways leading to inhibition of decomposition and pyrolysis.

The development of calorimetric techniques based on the principle of oxygen depletion has greatly improved fire testing and research because it quantifies the heat release associated with real burning [1] [2]. The cone calorimeter, [3] [4] developed at the National Bureau of Standards (NBS), now the National Institute of Standards and Technology (NIST), has been widely used for assessing the flammability of polymeric materials. This method was primarily developed for measuring the rate of heat release from a burning object as a function of incident flux [5]. The external radiation source is intended to simulate the effect of a burning object in close proximity. Interpretation of cone calorimeter data has not been adequately addressed within the fire retardant community [6], however, there is still a growing reliance on the instrument [7] [8] for the initial screening and subsequent assessment of new flammability modified materials. For example, the use of mineral fillers, such as aluminium hydroxide $[9,10]$ and nanofillers $[11,12]$ will change both physical and decomposition behaviour.

A number of studies [13] [14] [15] have effectively demonstrated that a numerical pyrolysis model can be used to determine the relationships between the fundamental physical and chemical properties of polymeric materials and their gasification behaviour. Typically, the model is used to calculate the mass loss rate of a one-dimensional sample of solid fuel exposed to a uniform heat flux. ThermaKin is an example of such a model, which has been effectively utilised as a practical tool for the prediction and/or extrapolation of the results of fire calorimetry experiments [16] [17] [18] [19]. The model, which combines the absorption and transfer of thermal energy with Arrhenius kinetics for the decomposition of the polymer, predicts the overall behaviour of a pyrolysing object through mass and energy conservation equations. These equations are formulated in terms of rectangular finite elements, each element being characterised by component mass and temperature. Additionally, the model describes the transport of gaseous products through the condensed phase and follows changes in the volume of the bulk material.

For thermally thick solids (typically, thicknesses above $15 \mathrm{~mm}[20]$ ) the thermal inertia, $k \rho c$, the product of thermal conductivity $(k)$, density $(\rho)$, and specific heat $(c)$, of a material governs its ignition and flame spread properties. This determines the rate of rise in surface temperature and consequently, the time to ignition [21]. The time to ignition $\left(t_{i g}\right)$ of a thermally thick solid exposed to a constant net heat flux $Q_{R}=Q_{\text {ext }}-\mathrm{CHF}$, where $Q_{\mathrm{ext}}$ is the external heat flux from fire or radiant heater and $\mathrm{CHF}$ is the critical heat flux for ignition, has been expressed in Equation 1.

$$
t_{i g}=\frac{\pi}{4} k \rho c \frac{\left(T_{i g}-T_{0}\right)^{2}}{\dot{Q}_{\hat{R}}{ }^{2}}
$$

[Equation 1]

where $T_{i g}$ and $T_{0}$ are the ignition and ambient temperatures, respectively. The time to ignition of a thermally thin solid exposed to a constant net heat flux has also been expressed in Equation 2. 


$$
t_{i g}=\rho c \tau \frac{\left(T_{i g}-T_{0}\right)}{\dot{Q}_{\hat{R}}}
$$

[Equation 2]

Where $\tau$ refers to material thickness. Equations 1 and 2 follow from the concept of a constant ignition temperature $T_{\text {ign }}$ and temperature-independent thermal inertia. Once ignition has occurred and a flame is established on the surface, the net heat flux becomes $Q_{R}=Q_{\text {ext }}+Q_{\text {flame }}-C \mathrm{CF}_{\mathrm{b}}$, where $Q_{\text {flame }}$ is the additional heat flux supplied by the flame and $\mathrm{CHF}_{\mathrm{b}} \approx \sigma T_{b}^{4}$ is the critical heat flux for burning in terms of the surface burning temperature $T_{\mathrm{b}}$ and the Boltzmann radiation consant $\sigma$. It has been shown that $T_{b} \approx T_{p}$ where $T_{p}$ is the pyrolysis temperature measured in laboratory thermal analysis experiments using small samples and constant heating rates [22]. Thus, polymers with high pyrolysis temperatures reradiate more of the incident heat flux from the heater and flame back to the surroundings, and the net heat flux that drives the burning process is reduced accordingly.

The Arrhenius rate constant, $k(T)=A \exp \left[-E_{\mathrm{a}} / \mathrm{RT}\right]$ is a reasonable descriptor of the temperature dependence of the rate of polymer thermal decomposition. The kinetic parameter $A\left(\mathrm{~s}^{-1}\right)$ represents the frequency of chemical bond breaking reactions in the polymer at temperature $T$ while the activation energy $E_{\mathrm{a}}$ represents the thermal energy barrier that must be overcome to break the chemical bonds and produce fuel gases. It has recently been demonstrated for a range of common polymers that the thermal decomposition temperature or peak pyrolysis rate temperature $\left(T_{p}\right)$ measured in thermal analysis experiments such as pyrolysis combustion flow calorimetry (PCFC) [23] or thermogravimetric analysis (TGA) has a large effect on ignition and burning [22][23]. Equation 3 is a derived result [22] that shows that the peak pyrolysis temperature in constant heating rate experiments such as TGA or PCFC is defined by an activation energy $\left(E_{a}\right)$ and Arrhenius factor $(A)$ that are not independent:

$$
T_{p}=\frac{E_{a}}{R \ln \left[\frac{A}{k_{p}}\right]}
$$

[Equation 3]

In Equation 3, $R$ is the gas constant and $k_{p}=k\left(T_{\mathrm{p}}\right)=A \exp \left[-E_{\mathrm{a}} / \mathrm{R} T_{\mathrm{p}}\right]=\beta \mathrm{E}_{\mathrm{a}} / \mathrm{R} T_{p}^{2}$ is the value of the kinetic rate constant at $T_{\mathrm{p}}$ measured for a milligram-size sample at a constant rate of temperature rise $\beta=\mathrm{d} T / \mathrm{d} t$ derived from a semi-exact solution of the Arrhenius temperature integral [22]. Since surface heating rates of polymers burning in a cone calorimeter at $50 \mathrm{~kW} / \mathrm{m}^{2}$ external heat flux are comparable to those used to determine $A$ and $E_{\mathrm{a}}$ in PCFC or thermogravimetric analyses [22], $\beta \approx 1$ $\mathrm{K} / \mathrm{s}$, and since $\mathrm{R} T_{p}^{2} / \mathrm{E}_{\mathrm{a}} \approx 20 \mathrm{~K}$ (typically), a constant value, $k_{\mathrm{p}}=\left(1 \mathrm{~K} \mathrm{~s}^{-1}\right) /(20 \mathrm{~K})=0.05 \mathrm{~s}^{-1}$ was used in Equation 3 to calculate the pyrolysis temperatures in Table 1 for $A$ and $E_{\mathrm{a}}$ used in ThermaKin (also shown in Table 1). It has been proposed that uncertainty in the Arrhenius parameters manifests itself as uncertainty in modelling the fire response of polymers [22]. The processes modelled by ThermaKin have been summarised in Figure 1. For this study, radiant heat from above the sample is absorbed, emitted or reflected, and the condensed phase heat transfer process is modelled through the solid. The resulting temperature increases drives endothermic decomposition processes, leading to the gasification of volatile fuel components. When a critical mass flux for ignition is reached, ignition will occur, and the incident radiant flux is augmented by radiation from the flame. Thereafter, quasi-steady state conditions pertain, until the sample is so thin that it has no more capacity to absorb heat, and the rate of pyrolysis increases. 


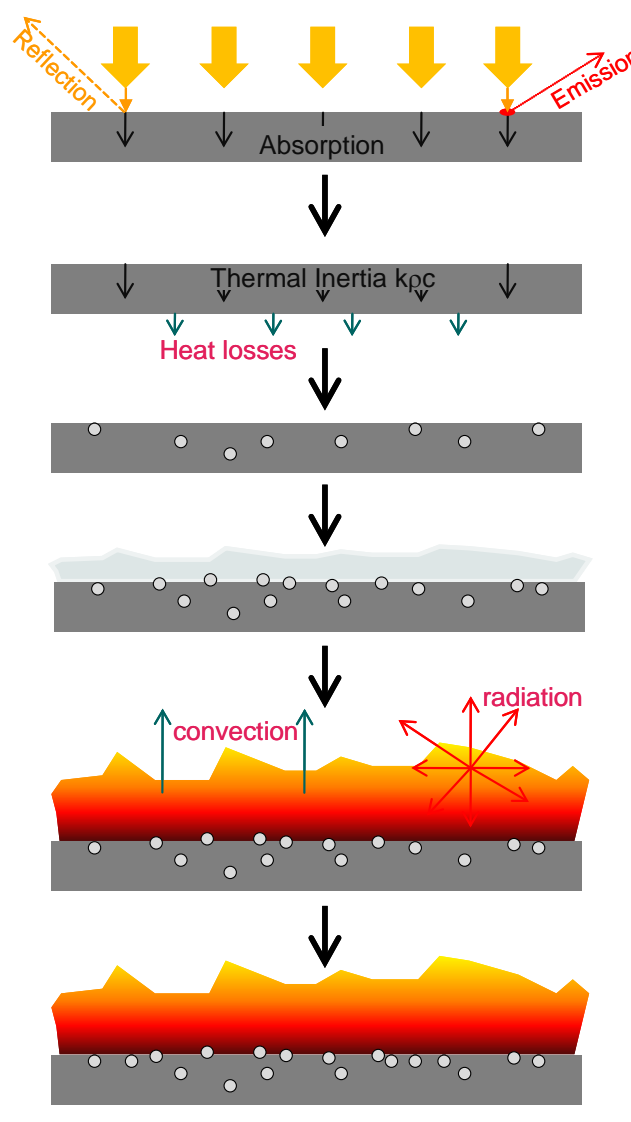

Infrared Radiation - Absorption,

reflection, emission

Heat transfer through solid - thermal inertia $\mathrm{k} \rho \mathrm{C}$

Endothermic thermal decomposition and gasification First Order Arrhenius kinetics

Gas transport leading to critical mass flux

Ignition

Convective and Radiative Heat Transfer

Steady Burning - Rate of fuel pyrolysis controlled by radiation from flame

Figure 1. Schematic of processes occurring in the cone calorimeter, as modelled by Thermakin

This present study utilises ThermaKin as a means of relating the physical properties of a material to its HRR history in a cone calorimeter.

\section{Modelling}

The effect of physical properties on the fire behaviour of non-charring polymers was investigated using a one-dimensional pyrolysis model, ThermaKin; a complete description of the model's mathematical formulation and numerical algorithms has already been reported [16].

A sensitivity analysis has been carried out by the model's developers to determine the relative importance of individual properties [18]. Within ThermaKin, changes to the fuel are accounted for as a change in the component. Each component is characterised by its physical state, density, heat capacity, thermal conductivity, gas transfer coefficient, emissivity and absorption coefficient. The model ignores changes in thermal conductivity resulting from changes in melt flow behaviour on heating. The chemical processes occurring are characterised through the reaction's activation energy and Arrhenius factor. The energy balance assumes that radiant heat may be absorbed or reflected by the sample, and then either conducted through it resulting in a localised temperature increase, or re-radiated from the surface. Higher temperatures will result in gasification forming vapour phase fuel which can $b$ ignited and then burns, transferring some radiant heat back to the sample. From the sensitivity analysis [18], it was established that for most synthetic polymers, the thermal, optical and chemical properties varied only within limited ranges. To demonstrate this, the lower, average and upper boundaries of each parameter were determined from experimental techniques and reported values [18]. These are shown in Table 1. The study also determined that some parameters had a greater influence on time to mass loss, peak mass loss and average mass loss rate and 
subsequently time to ignition, peak heat release rate and average HRR when determined using the material's effective heat of combustion. The authors conclude that knowledge of the activation energy, Arrhenius factor, heat of decomposition and char yield was central to the accuracy of simulations, with knowledge of absorption coefficient and reflectivity also being fairly important.

\begin{tabular}{|l|c|c|c|}
\hline \multicolumn{1}{|c|}{ Parameter } & Lower & Average & Upper \\
\hline Density $(\rho) / \mathrm{kg} / \mathrm{m}^{3}$ & 830 & 1300 & 1830 \\
\hline Thermal Conductivity $(\mathrm{K}) / \mathrm{W} \mathrm{m}^{-1} \mathrm{~K}^{-1}$ & 0.11 & 0.24 & 0.42 \\
\hline Heat Capacity $(\mathrm{c}) / \mathrm{J} \mathrm{kg}^{-1} \mathrm{~K}^{-1}$ & 1700 & 2300 & 2900 \\
\hline Reflectivity $(\mathrm{r})$ & 0.06 & 0.12 & 0.25 \\
\hline Absorption Coefficient $(\alpha) / \mathrm{m}^{-1}$ & 1100 & 3800 & 9000 \\
\hline Heat of Decomposition $\left(\mathrm{h}_{\text {dec }}\right) / \mathrm{kJ} \mathrm{kg}^{-1}$ & 0.1 & 1.3 & 2.5 \\
\hline Heat of Combustion $\left(\mathrm{h}_{\mathrm{c}}\right) / \mathrm{MJ} \mathrm{kg}^{-1}$ & 15.93 & 24.99 & 44.60 \\
\hline Pre-Exponential Factor $(\mathrm{A}) / \mathrm{s}^{-1}$ & $1.0 \times 10^{8}$ & $1.0 \times 10^{14}$ & $1.0 \times 10^{20}$ \\
\hline Activation Energy $\left(\mathrm{E}_{\mathrm{a}}\right) / \mathrm{J} \mathrm{mol}{ }^{-1}$ & $8.90 \times 10^{4}$ & $2.05 \times 10^{5}$ & $3.67 \times 10^{5}$ \\
\hline Pyrolysis Temperature $\left(\mathrm{T}_{\mathrm{p}}\right) / \mathrm{K}$ & 500 & 700 & 900 \\
\hline
\end{tabular}

Table 1. Sensitivity Analysis - Values for Lower, Average and Upper Parameter Boundaries for Common Polymers

The ThermaKin model was set up as follows. The material (assumed to be an average polymer) was represented at all times by the average values - the property values and reaction parameters were varied within the boundaries of observed behaviour to give a lower, average and upper scenario for each. The material was specified to decompose via a first order reaction, defined by the Arrhenius parameters and heat of decomposition. It was assumed that the reaction had only gaseous products, which were instantly removed from the condensed phase, leaving no char residue.

The burning was modelled to represent a scenario where the top surface of a one-dimensional material is exposed to a constant radiative heat flux. Natural convection was simulated by subjecting the top layer to a convection coefficient of $10 \mathrm{~W} \mathrm{~m}^{-2} \mathrm{~K}^{-1}$ with an ambient temperature of $300 \mathrm{~K}$. The mass flux for ignition was set at $1 \times 10^{-3} \mathrm{~kg} \mathrm{~m}^{-2} \mathrm{~s}^{-1}$ corresponding to the onset of piloted ignition for polymers under convective conditions [24]. The ignition process resulted in an additional $15 \mathrm{~kW} \mathrm{~m}^{-2}$ heat flux from the flame. The bottom surface remained insulated (to minimise heat loss effects) with a layer of glass wool set at a thickness of $1.5 \times 10^{-2} \mathrm{~m}$, following the standard cone calorimeter set up [3]. The thickness of the material was set at $2.5 \times 10^{-3} \mathrm{~m}$ and the applied heat flux at $50 \mathrm{~kW} \mathrm{~m}^{-2}$.

The mass loss rate for each scenario was obtained by numerical differentiation of the material mass versus time data - outputs of the ThermaKin model. To obtain HRR for a 'generic' polymer, the mass loss rate was multiplied by the heat of combustion for PMMA (a single decomposition product polymer which leaves no solid residue) obtained from literature to be $24.99 \mathrm{KJ} \mathrm{g}^{-1}$ [25]. The choice of PMMA was somewhat arbitrary, but for the purpose of comparison, a single ... value must be used. The values for the net heat of combustion were also varied, as shown in Table 1. Polyethylene (PE) was selected for the upper boundary and polyoxymethylene (POM) for the lower boundary. 


\section{Results and Discussion}

Influence of Physical Properties

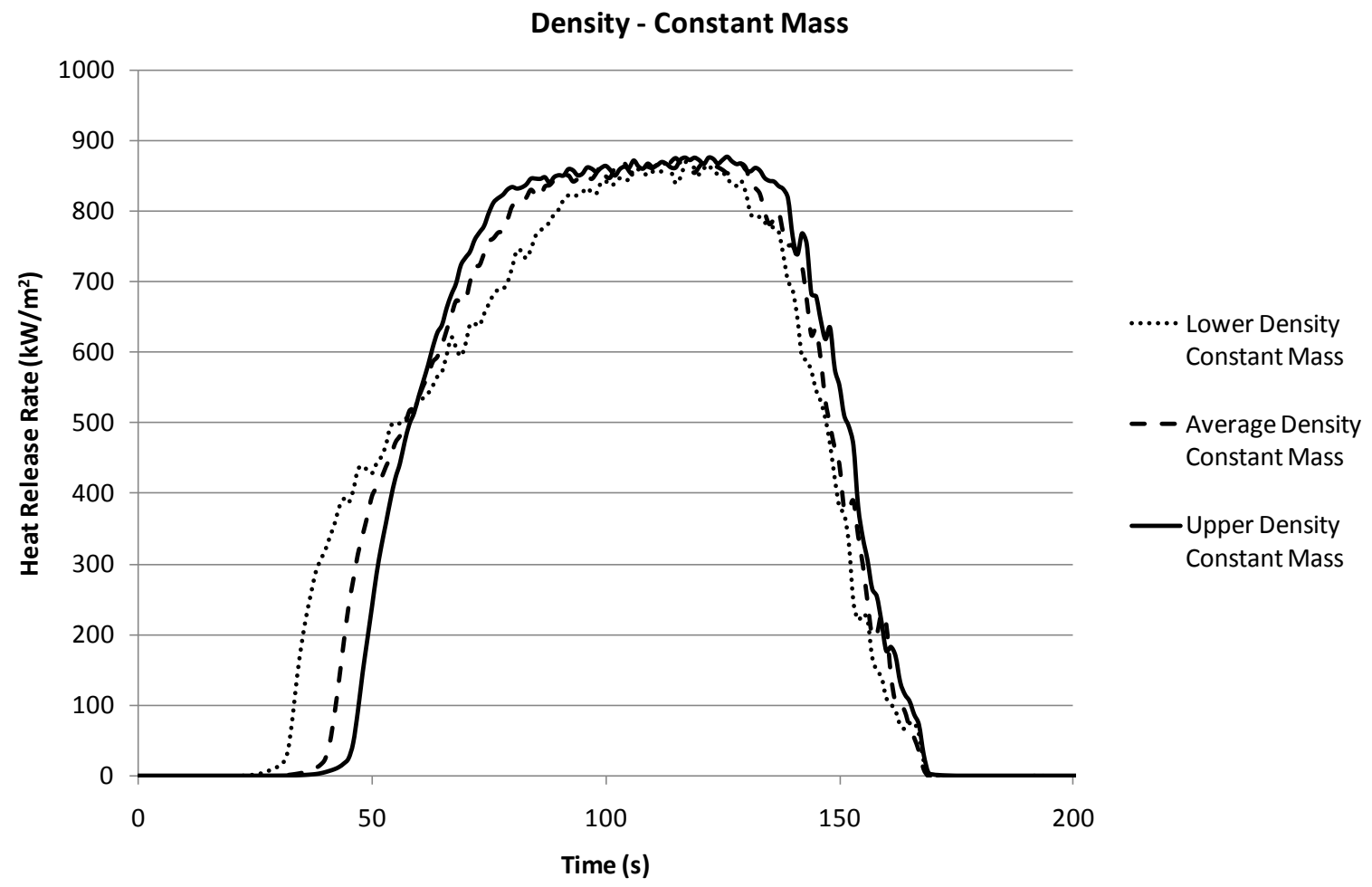

Figure 2. Effect of Density (with Constant Mass) on Cone Calorimeter HRR Histories

The physical properties input into the ThermaKin model are density, thermal conductivity and heat capacity. The effect of density on HRR histories is shown in Figure 2. The ThermaKin input is actually based on a defined volume and density, from which mass is implicit. For the purpose of this study, it is easier to compare samples of constant mass, so three samples of different density have been compared at constant mass. It is important to note that all the polymers whose parameters were identified were solids, not foams and other expanded materials containing voids of air or gas; which would have a more profound effect. The HRR corresponding to the lower limit for density gives a shorter time to ignition and the upper limit gives the longest time to ignition. The low density materials has a high surface temperature, reaching the critical pyrolysis flux first, but also a larger thermal gradient through its bulk, and hence requires more heat to get the remainder of the sample up to the pyrolysis temperature. This can be seen in the longer time to reach the peak HRR than the average or high-density polymer. The only effects of density $(\rho)$ are on the time to ignition and the time to peak HRR. 


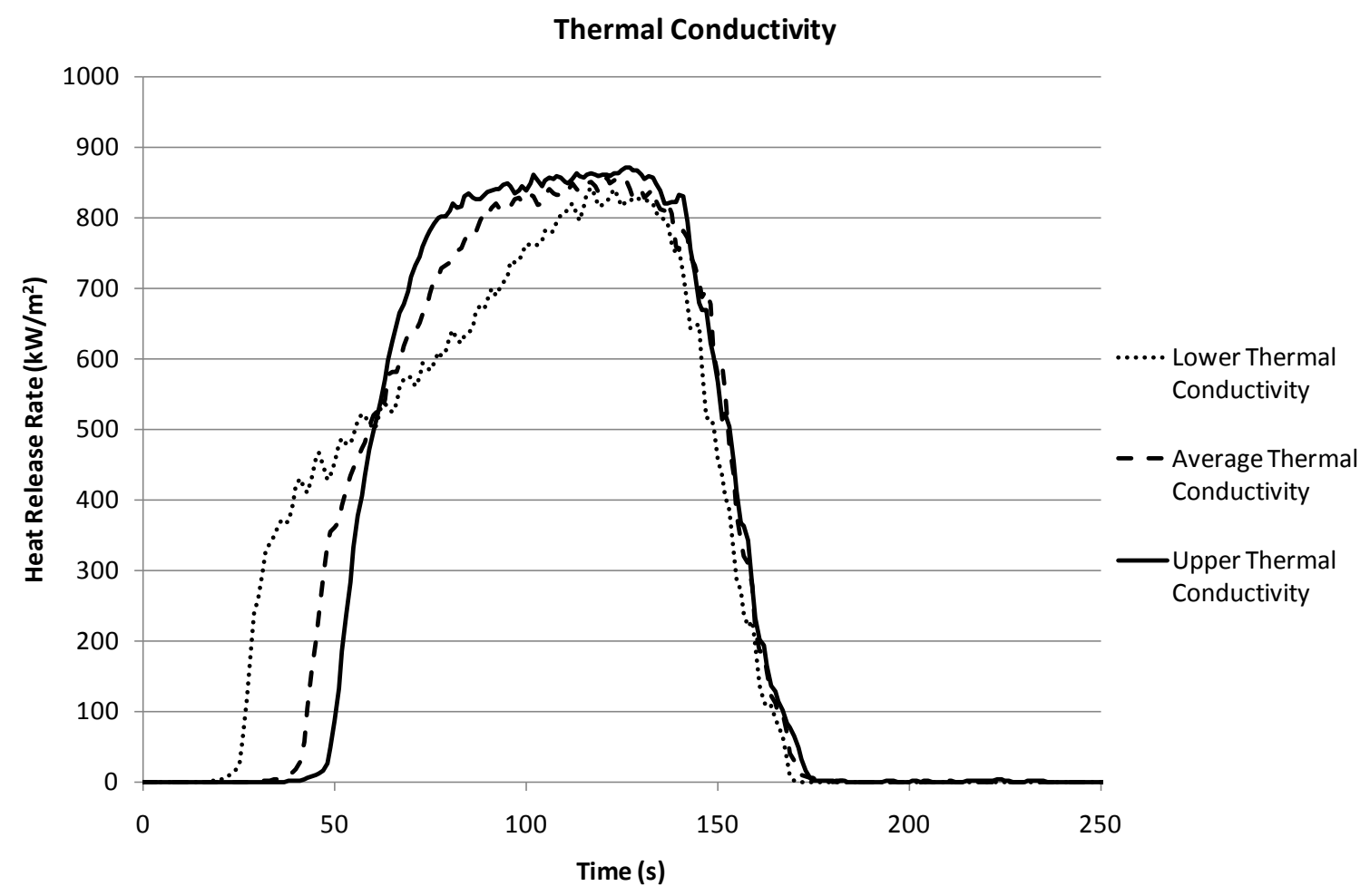

Figure 3. Effect of Thermal Conductivity on Cone Calorimeter HRR Histories

The effect of thermal conductivity on HRR histories is shown in Figure 3. Thermal conductivity relates to a material's ability to conduct heat and transfer energy through its bulk for scenarios where a temperature gradient exists. A low thermal conductivity indicates less ability to dissipate heat through the material. As a result, more heat remains concentrated at the surface and therefore the material ignites earlier. Again, the HRR history corresponding to the first sample to ignite, in this case also having the lower limit for thermal conductivity takes longer to reach its peak value in comparison to the HRR history for the upper limit of thermal conductivity. A material with a higher thermal conductivity allows heat to be dissipated effectively through the bulk and therefore, due to the build up of heat within the system, the material does ignite it will burn more quickly. A material with a low thermal conductivity is more likely to show thermally thick burning behaviour, indicating that the bulk of the fuel acts as an almost infinite heat sink during the early stages of burning. Similarly, a material with a greater thermal conductivity is more likely to show thermally thin burning. As a result, this gives a longer time to peak HRR as each layer ignites and burns as a separate entity. 


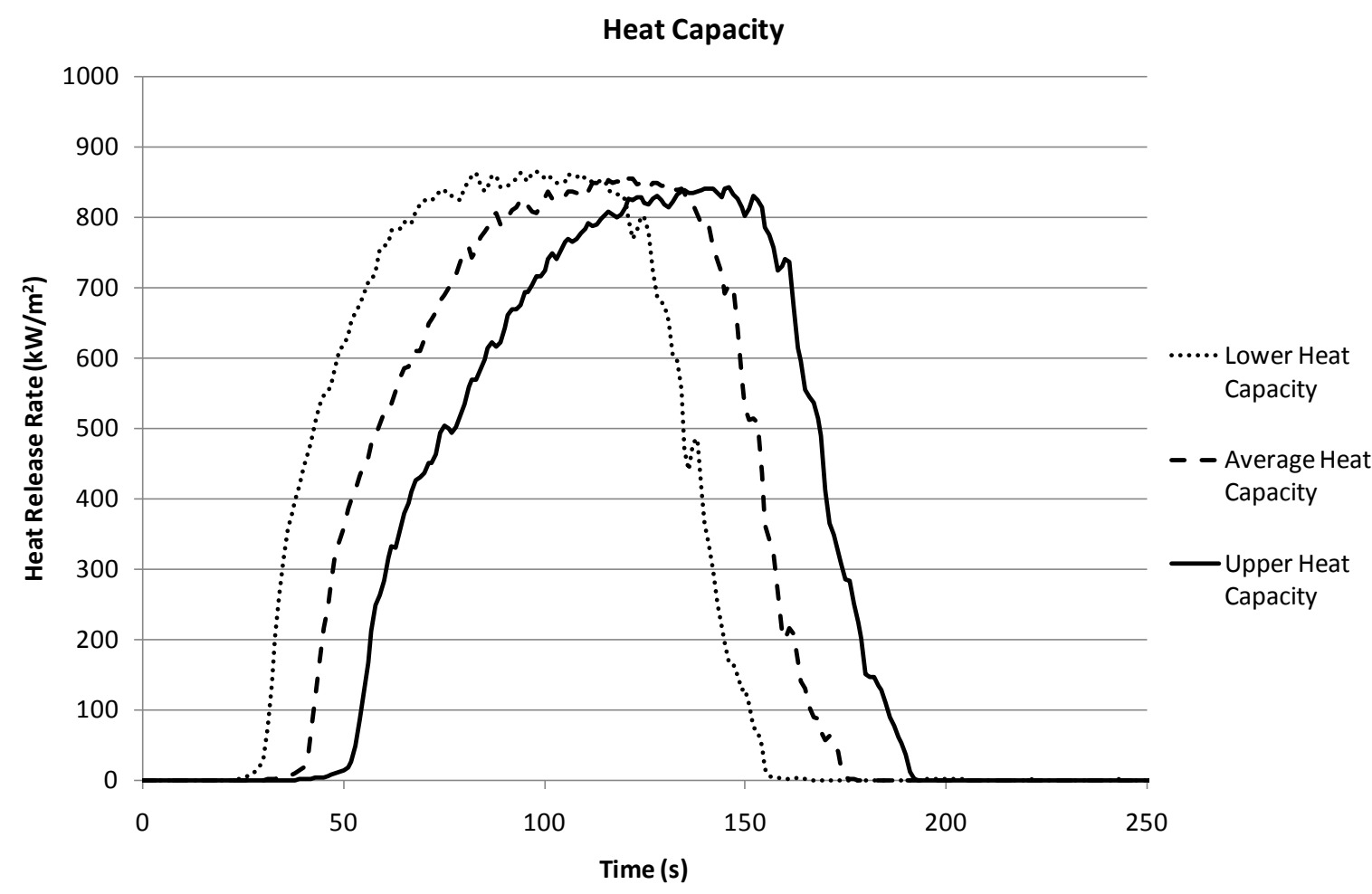

Figure 4. Effect of Heat Capacity on Cone Calorimeter HRR Histories

The effect of heat capacity on HRR histories is shown in Figure 4. The heat capacity of a material refers to the amount of energy required to raise the temperature of one kilogram of polymer by $1 \mathrm{~K}$. A lower heat capacity indicates that less energy is required to raise the temperature of the surface to ignition temperature. A low heat capacity material will have a low thermal inertia $(\mathrm{kpc})$ and hence the upper layers will reach the critical surface temperature for ignition more quickly than a material with higher heat capacity (or greater thermal inertia). At a constant external heat flux, this is governed by the time of exposure, which is balanced by the energy required for gasification (the heat of decomposition). The peak HRR and the time of test remain constant. 


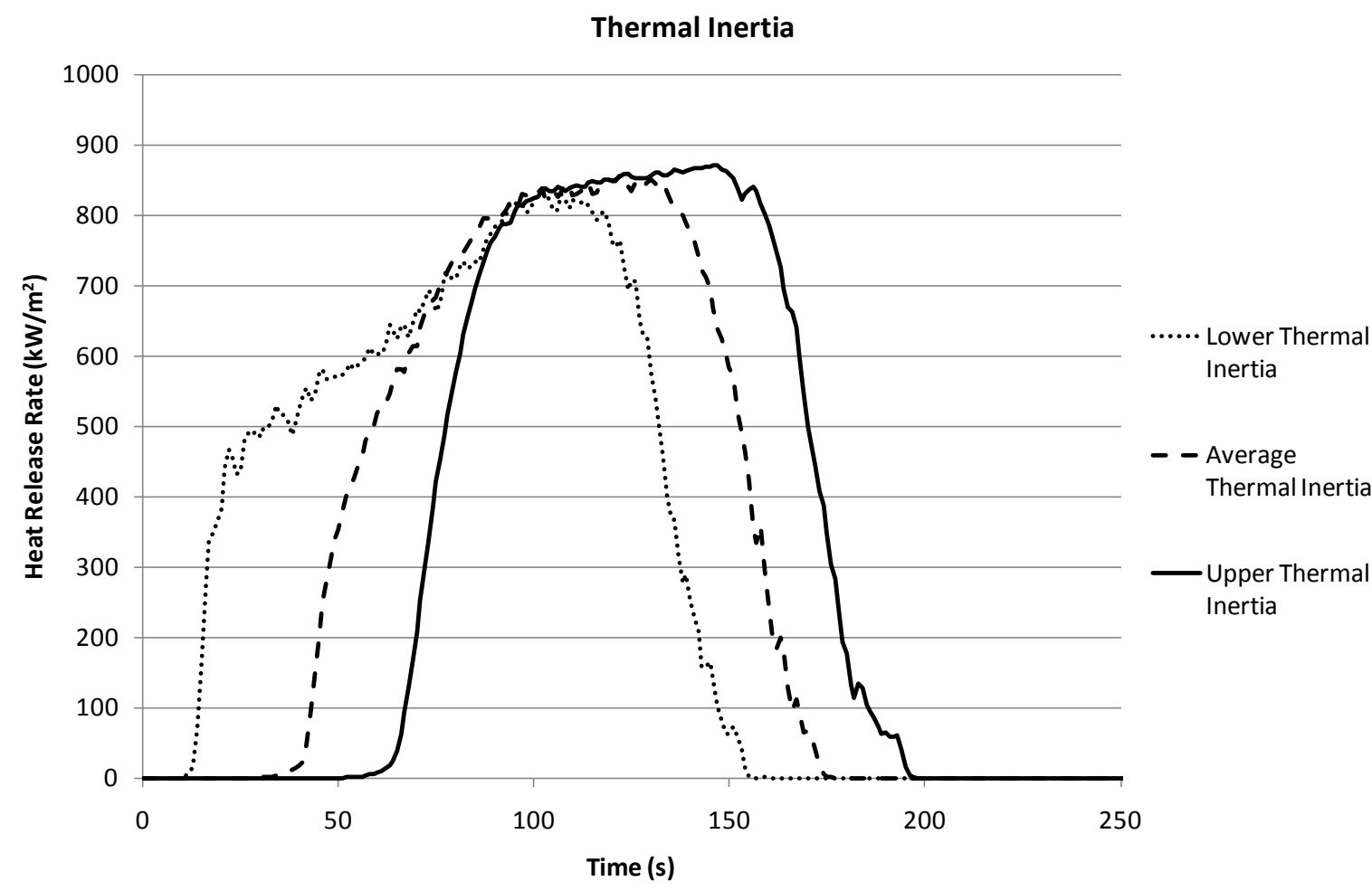

Figure 5. Effect of Thermal Inertia on Cone Calorimeter HRR Histories

The overall effect of the three parameters, taking the lowest, average and highest of each as the effect of thermal inertia on HRR histories is shown in Figure 5. This shows greater differences in both the shape and position of the respective HRR histories. The very short time to ignition for the lower thermal inertia sample, coupled with the poorer heat transfer results in ignition occurring in a material which is cooler underneath. As burning penetrates through the material, less heat is required to bring the remainder to pyrolysis temperature, so more is available for pyrolysis. This is seen as a steady increase in the HRR history. In contrast, the high thermal inertia sample a long ignition delay time, and a very steady, high HRR. 


\section{Influence of Optical Properties}

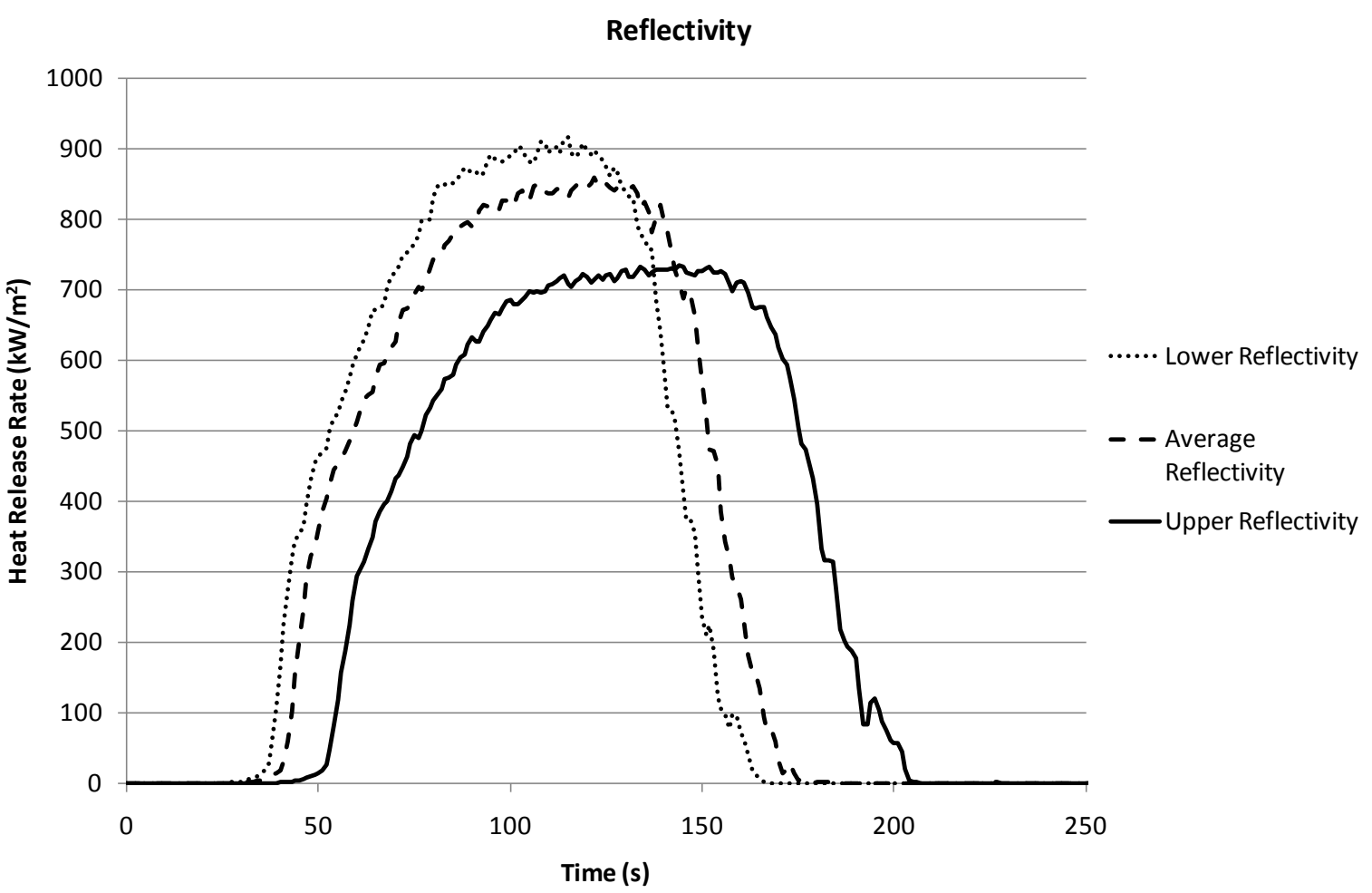

Figure 6. Effect of Reflectivity on Cone Calorimeter HRR Histories

The optical properties employed by the ThermaKin model are reflectivity and absorption coefficient. The process of absorption of radiant heat depends on the optical properties of the sample. A mirrorlike finish would not absorb any radiation, and would never ignite. Absorption is essentially a molecular process where a photon of radiation results in the excitation of a specific atom or molecule. The infrared radiation from the cone heater at $50 \mathrm{~kW} \mathrm{~m}^{-2}$ results in vibration and excitation which eventually relaxes down to increased thermal energy, or a higher temperature. The effect of reflectivity on HRR histories is shown in Figure 6. Reflectivity refers to the amount of infrared radiation that is reflected from the material's surface or essentially, how the surface interacts with external heat fluxes from the cone heater and then from both the cone heater and the flame, subsequent to ignition. The HRR history corresponding to the upper limit for reflectivity shows a longer time to ignition. This is due to the fact that more energy is reflected and as a result, less energy is absorbed by the surface. In a system with a constant external heat flux, this also results in a lower peak of HRR, as less heat is available for decomposition and volatilisation, so the overall process is slower. In contrast the low reflectivity surface shows a shorter time to ignition, higher peak HRR and an overall shorter burning time. Given that these predictions are from unadulterated polymers, the addition of an additive or a change in the sample preparation (surface roughening) could have a profound effect on the HRR history just because of changes in the reflectivity. 


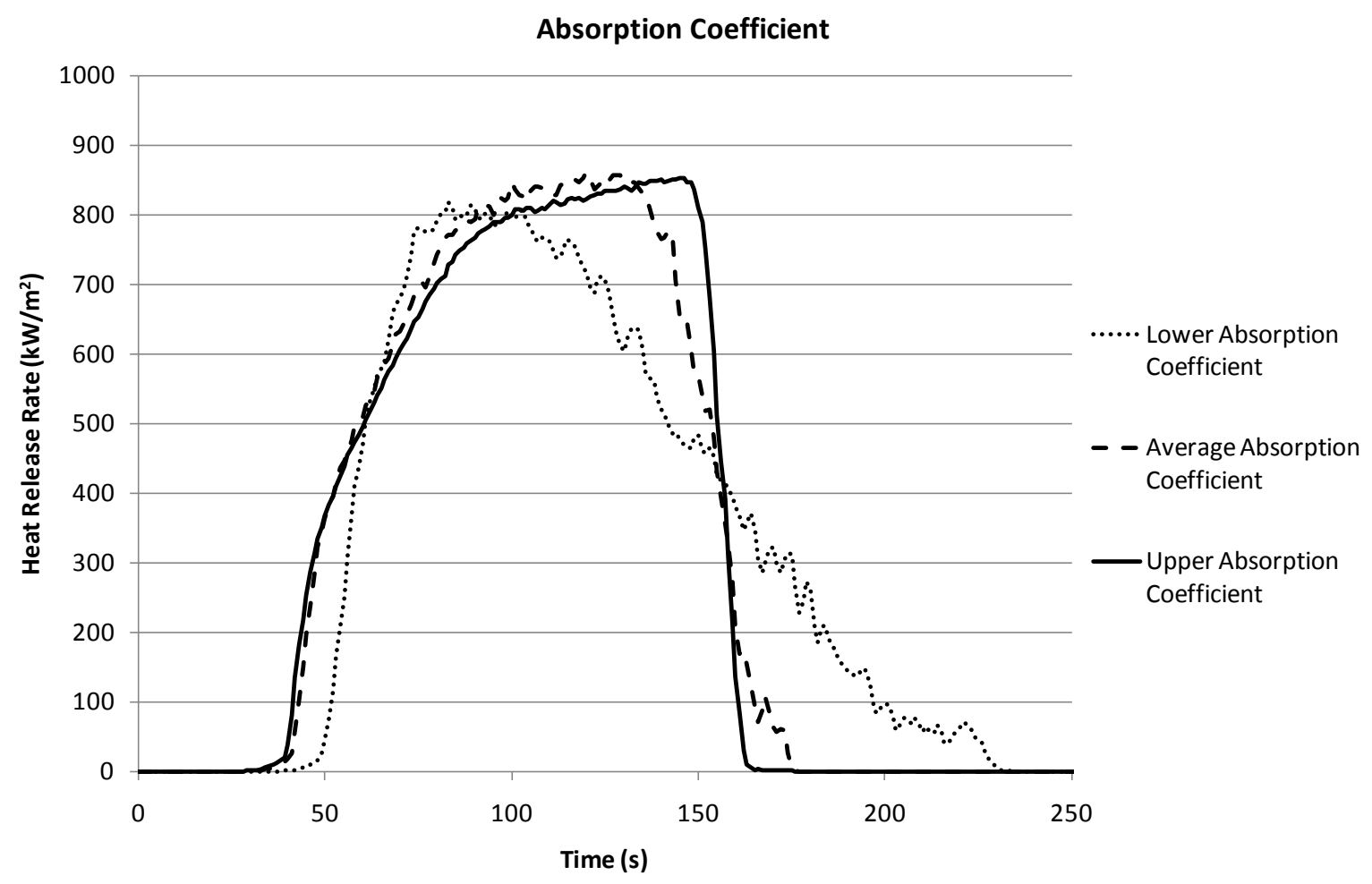

Figure 7. Effect of Absorption Coefficient on Cone Calorimeter HRR Histories

The effect of absorption coefficient on HRR histories is shown in Figure 7. A material's absorption coefficient refers to the amount of energy absorbed by the material. Certain polar bonds are good absorbers of infrared radiation, and if these are present, most of the heat will be absorbed by the surface layers. The absence of such absorbers will allow more heat to penetrate within the bulk of the polymer, and possibly even pass straight through it. The surface layers of a material with a large absorption coefficient will heat up much quicker than those of a material with a lower absorption coefficient. However, the non-reflected radiation which penetrates the sample without being absorbed will cause heating in lower layers. Thus, highly absorbing materials have an early time to ignition however the lower absorbing materials will have the shortest time to peak HRR. The HRR corresponding to the lower limit for absorption shows a longer time to ignition and a more progressive decrease from its peak of HRR to $0 \mathrm{~kW} \mathrm{~m}^{-2}$. This is because an increasing proportion of the radiation passes through samples as the thickness decreases. In practice, the absorption of polymers is likely to change during decomposition as the bonding changes, increasing the number of absorbing centres, so this type of behaviour is rarely observed. 


\section{Influence of Chemical Properties}

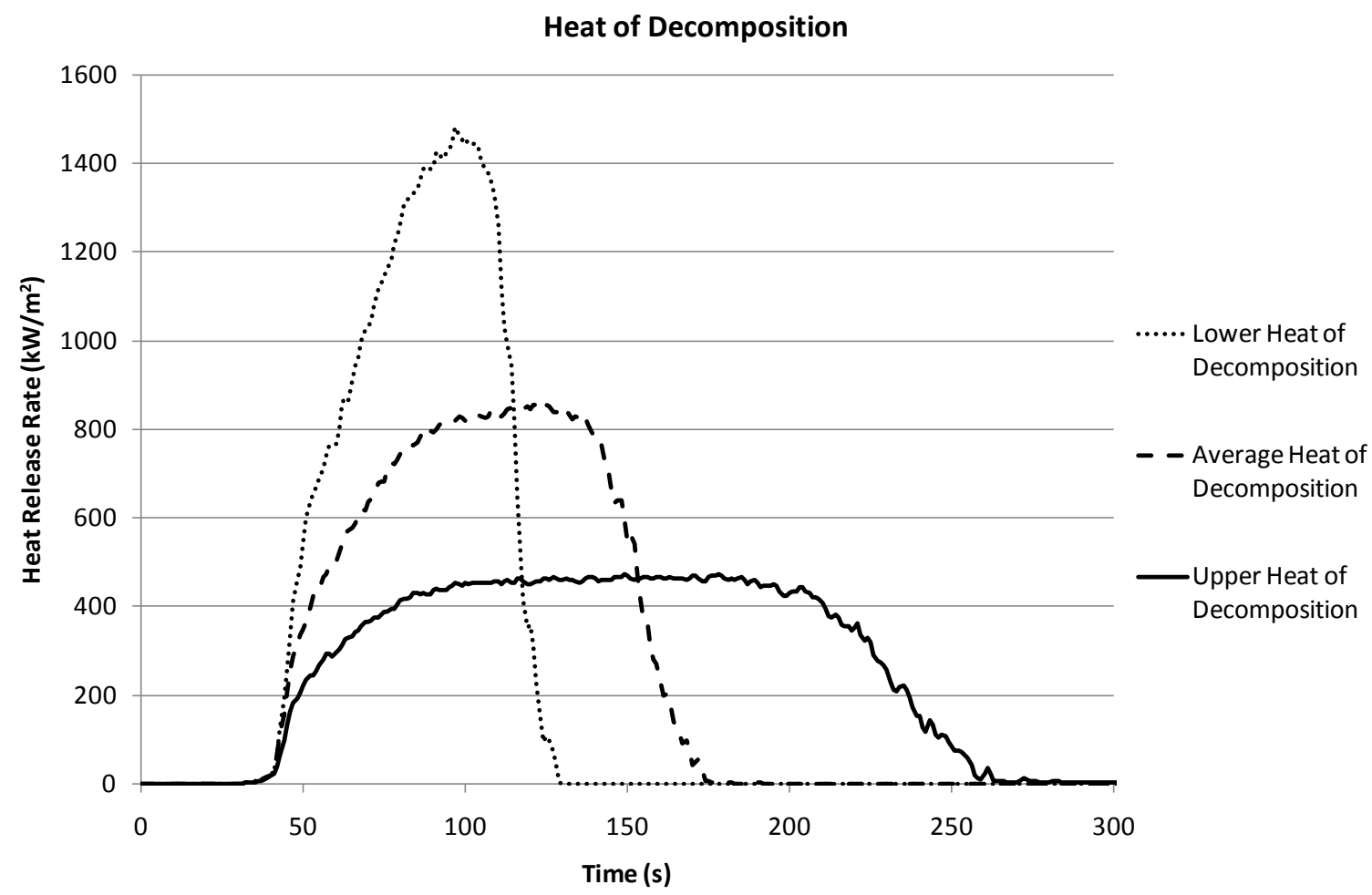

Figure 8. Effect of Heat of Decomposition on Cone Calorimeter HRR Histories

The chemical properties employed by the ThermaKin model are heat of decomposition, activation energy, Arrhenius factor and heat of combustion. The heat of decomposition, or heat of gasification describes the endothermic transition from condensed to gas phase fuel. It is analogous to the latent heat of vaporisation of a liquid, but prior to vaporisation the polymer must first breakdown into smaller, volatile fragments. The effect of heat of decomposition on HRR histories is shown in Figure 8. A simple energy balance exists between the heat of decomposition (or the heat required to produce the fuel) and the heat released by it. In thermally thick burning, at a constant heat flux, the rate of heat release is proportional to the rate of pyrolysis. If more heat is required to pyrolyse the fuel this will give a slower rate of pyrolysis and a lower, steadier HRR. The large differences in the shape of the heat release histories show the importance of the heat of decomposition parameter, which could also be described as the thermal stability of the polymer 


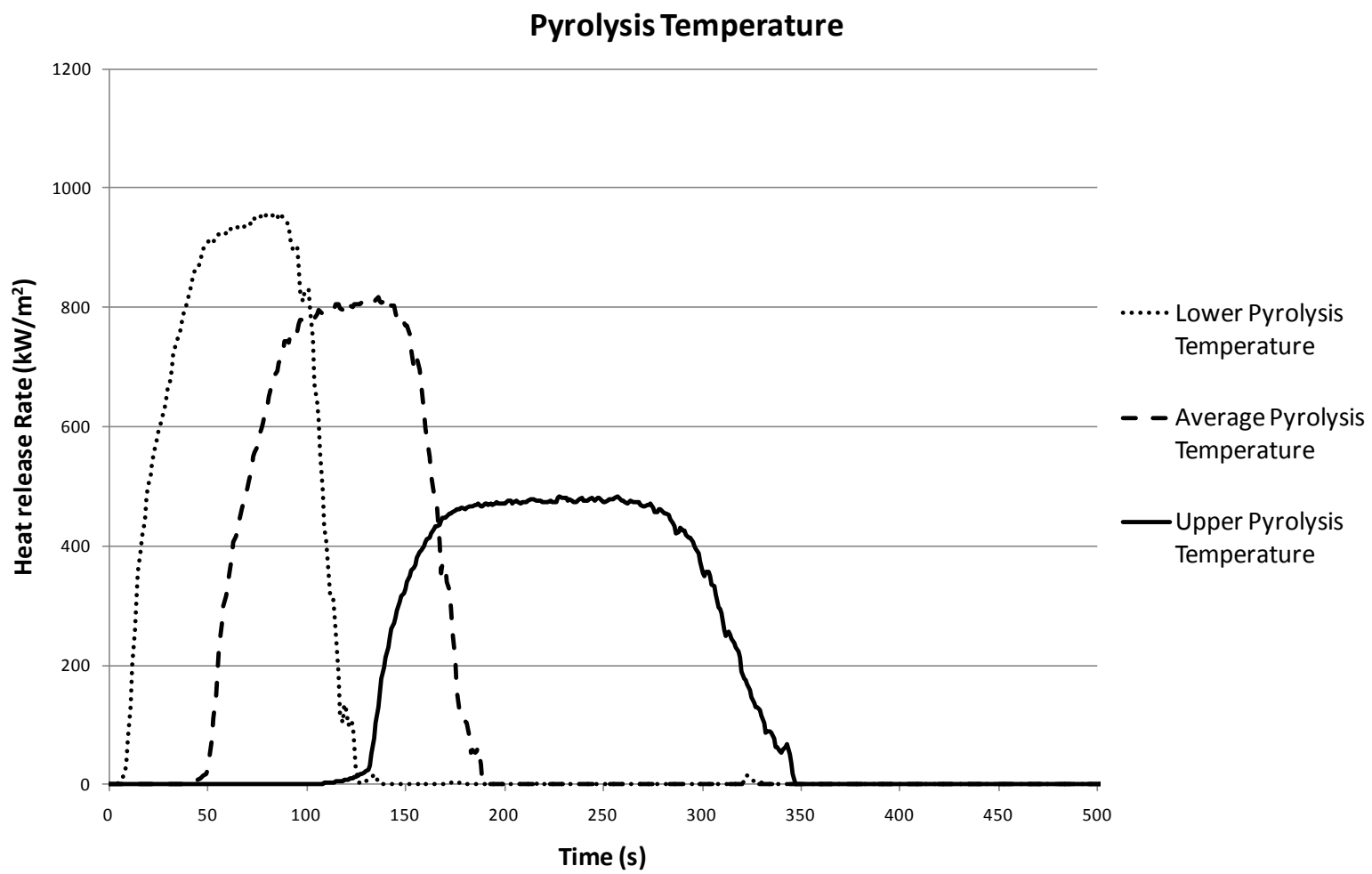

Figure 9. Effect of Pyrolysis Temperature on Cone Calorimeter HRR Histories

The values for $\underline{T}_{\mathrm{p}}$ in these simulations: 500,700 and $900 \mathrm{~K}$ correspond to the variation of polymer properties used for the sensitivity analysis, although in this case, values are rounded off to the nearest $100 \mathrm{~K}$. The effect of pyrolysis temperature expressed through the $A / E_{a}$ pair in Table 1 on the HRR histories calculated by ThermaKin is shown in Figure 9. The influence of high thermal stability (high $T_{\mathrm{p}}$ ) on the burning behaviour is obvious in both the time to ignition and the burning rate after ignition. High thermal stability increases the time to ignition because the critical mass flux is not reached until the surface approaches $T_{\mathrm{p}}$. High thermal stability also reduces the burning (heat release) rate because a larger fraction of the incident energy is reradiated from the surface at high $T_{\mathrm{p}}$ and the net heat flux is reduced accordingly. In the ThermaKin simulations, $Q_{\text {ext }}=50 \mathrm{~kW} \mathrm{~m}^{-2}, Q_{\text {flame }}=$ $15 \mathrm{~kW} \mathrm{~m}^{-2}$ and assuming $\mathrm{CHF}_{\mathrm{b}}=\sigma T_{p}^{4}$ the net heat flux would be $Q_{\mathrm{R}}=(1-\mathrm{r})\left(Q_{\mathrm{ext}}+Q_{\text {flame }}-\mathrm{CHF}_{\mathrm{b}}\right)=54$, 45 and $25 \mathrm{~kW} \mathrm{~m}^{-2}$ for $T_{\mathrm{p}}=500,700$ and $900 \mathrm{~K}$, respectively. The maximum HRR in Figure 9 decreases in rough proportion to these $\mathrm{CHF}_{\mathrm{b}}$ because less energy is available to drive the burning process as the thermal stability of the polymer increases. 


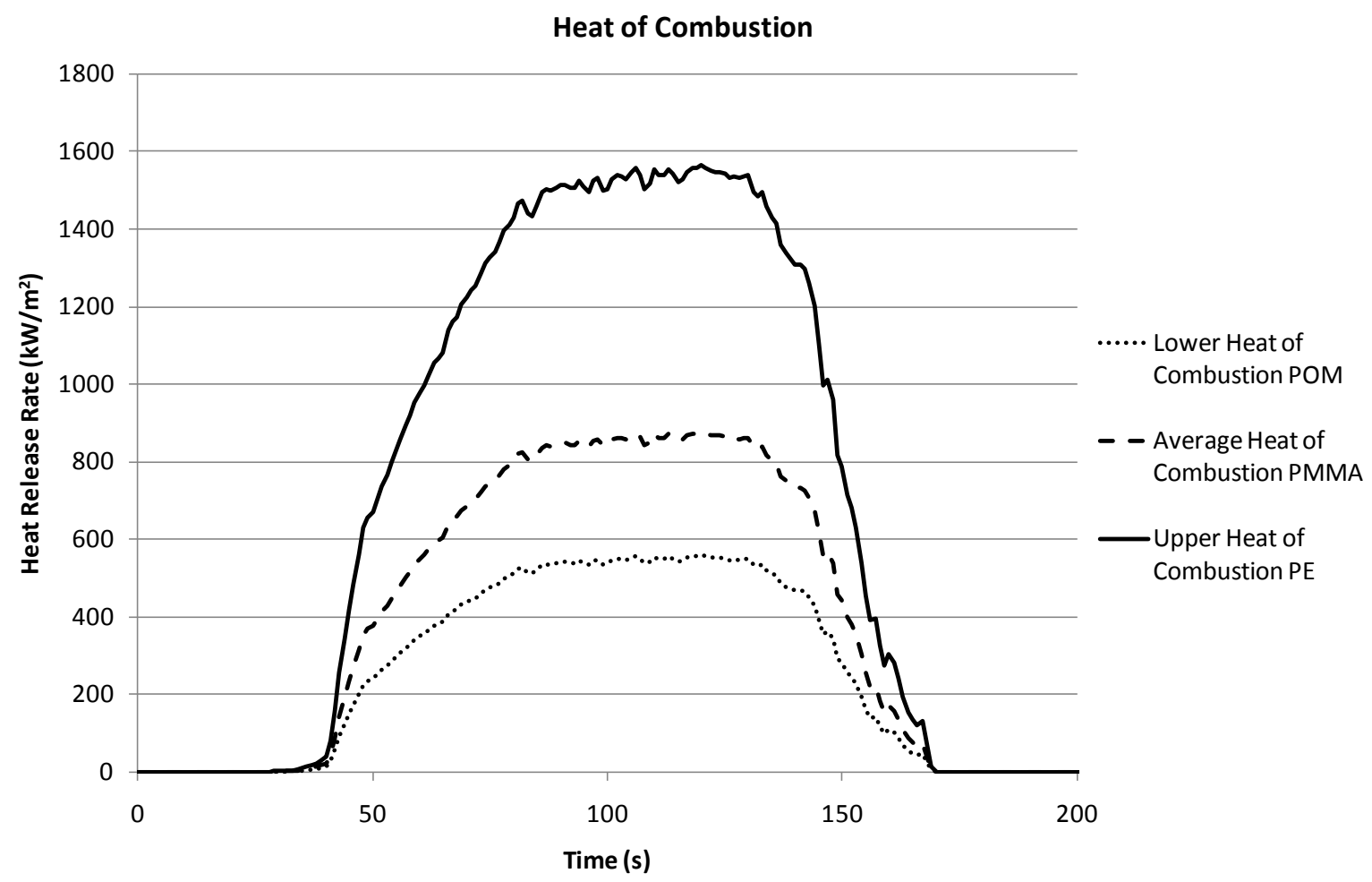

Figure 10. Effect of Heat of Combustion on Cone Calorimeter HRR Histories

The effect of heat of combustion on HRR histories is shown in Figure 10. The heat of combustion depends on the elemental composition of the material and its combustion efficiency. In many cases, the heat of combustion reported in literature is determined under rather artificial conditions of 25 atmospheres of pure oxygen in a bomb calorimeter. The sample with the highest heat of combustion, polyethylene (PE), contains just carbon and hydrogen, which release heat to form carbon dioxide and water. Lower heats of combustion are obtained from samples containing oxygen or other non-combustible elements. It is somewhat surprising to see that the heat of combustion has no influence on the modified HRR histories on the time of burning, and only affects the profile of HRR. 


\section{Conclusions}

Cone calorimetry is probably the single most important tool for the assessment of flammability behaviours. A number of parameters govern the burning behaviour, which could be subdivided into: ignitability and flame spread (a sources of repeated ignitions); HRR (the larger and earlier the peak of HRR the faster the rate of fire growth); and smoke and toxic gas production. Adequate screening is essential for the development of fire safe materials - this requires proper understanding of the results - in order to correlate the burning behaviour to the underlying physical properties. By separating the effects of physical properties, the more specific chemical effects of fire retardants can then be identified.

The Thermakin modelling of cone calorimeter behaviour presented here predicts the individual effect of the optical, thermal and chemical properties of the fuel. Additive fire retardants, usually added at loadings of $10-70 \%$ have a profound effect on the physical properties, changing the absorption, transfer of heat and decomposition behaviour, as well as inhibiting the gas phase free radical processes. This study examines the effect of typical variations in polymer properties on the HRR history.

The density of most polymers lies within a fairly narrow range and has a small influence on the time to ignition and time to peak of HRR, but in these predictions has no effect on the actual height of the peak. The thermal conductivity varies by a factor of 4 , and materials with the lowest thermal conductivity are predicted to have half the time to ignition and double the time to peak of heat release, as may be expected. The heat capacity of polymers varies over a narrow range, affecting the time to ignition but not the overall burning time or peak of heat release. The addition of most additives, particularly inorganic materials, will change the thermal inertia (the product of density, thermal conductivity and heat capacity) and this will influence the ignition and burning behaviour.

The optical characteristics of polymers, absorption and reflectivity vary by factors of 8 and 4 respectively, though surface coatings and additives could produce much larger differences. The absorption coefficient affects the shape of the heat release history, showing sharply decreasing absorbance by the lowest absorber as the sample becomes thinner. In practice, the absorbance of infrared radiation is likely to change during decomposition, with an increase in absorbing centres as the chemical structure becomes more heterogeneous, tending to mitigate this effect. The surface reflectivity affects both the time to ignition and the peak HRR, but not the total heat released (as may be expected), so highly reflective polymers take longer to ignite and burn more slowly.

The chemical composition of the polymer exerts the greatest influence on its burning behaviour. The heat of decomposition (or energy required for gasification) varies over more than two orders of magnitude, has no effect on the time to ignition, but a strong effect on the peak of heat release and the burning time. The pyrolysis temperature, which relates to the rate of gasification (or fuel production) has only been varied from $500-900 \mathrm{~K}$ but has the strongest influence on both the time to ignition and the peak of HRR. This is the single most important parameter for predicting the burning behaviour of a polymer. Finally the heat of combustion of the gas phase fuel affects the peak HRR, but not the time to ignition (as may be expected) or the burning time (which is more surprising since presumably a lower heat of combustion is accompanied by a decrease in thermal feedback).

The effects of flame retardant chemicals on the burning rate of polymers are incorporated into ThermaKin by including reactions that generate products whose properties have the desired (observed) effect. For example, intumescence can be introduced into the model as a reaction product (component) having properties (density, thermal conductivity, heat capacity, mass transport coefficient, in-depth absorption of radiation, etc) that may differ from the polymer but which 
reproduce the desired (observed) effect on the burning rate. The trigger for reaction from one component to another is temperature. Thus, within the model of the burning material in the cone calorimeter, an intumescent foam could form first in the uppermost part of the material, and then the foam/non-foam interface will progressively penetrate downwards into the bulk of the material as the temperature rises. The only limit to the number of intermediate products that may be included is the availability of physical property data for them. Likewise, the optical properties of the flame retardant may be represented by an inert component with an emissivity that is higher (such as char or carbon nanotubes) or lower (such as titanium dioxide $\left(\mathrm{TiO}_{2}\right)$, mica or glass fibres) than the emissivity of the matrix polymer so as to absorb or reflect more of the incident radiant energy, respectively, at the surface or in depth. As the polymer matrix recedes, the solid component (char, $\mathrm{TiO}_{2}$ etc.) will concentrate at the surface and change its emissivity. The effect of gas phase active flame retardants on burning rate can be captured empirically by adjusting (or measuring) the effective heat of combustion of gaseous products and/or the flame heat flux back to the material surface, which will be a function of the soot concentration and flame temperature.

Overall, the Thermakin model provides a useful tool for understanding how the physical properties of polymers influence their burning behaviour. The ability to isolate individual physical properties shows great potential to optimise formulations on a microscale, prior to screening on a cone calorimetry scale.

\section{Acknowledgements}

One of us (PP) would like to thank the Engineering and Physical Science Research Council (EPSRC) for the award of a CASE PhD Studentship (No. 07001444).

\section{References}

1 Hugget, C., (1980), Estimation of the Rate of Heat Release by Means of Oxygen Consumption Measurements. Fire and Materials. 4(2), pages 61-65.

2 Babrauskas, V., (1982), Development of the Cone Calorimeter. A Bench-Scale Heat Release Rate Apparatus Based on Oxygen Consumption (NBSIR 82-2611). US National Bureau of Standards.

3 ISO 5660-1: 1993. Fire Tests on Building Materials and Structures. Part 15-Method for Measuring the Rate of Heat Release of Products.

4 ASTM E 1354-97, Standard test method for heat and visible smoke release rates from materials and products using an oxygen consumption calorimeter. American Society for Testing of Materials, West Conshohocken, PA (1997).

5 Nelson, M. I., Brindley, J., and McIntosh, A.C., (1996), Polymer Ignition. Mathematical and Computer Modelling. 24(8), pages 39-46

6 Schartel, B., and Hull, T.R., (2007), Application of Cone Calorimetry to the Development of Materials with Improved Fire Performance. Fire and Materials. 31, pages 327-354.

7 Babrauskas, V., and Peacock, R. D., (1992), Heat Release Rate: The Single Most Important Variable in Fire Hazard. Fire Safety Journal. 18(3), Pages 255-272.

8 Sacristán, M., Hull, T. R., Stec, A. A., Ronda, J. C., Galià and Cádiz, V., (2010), Cone Calorimetry Studies of Fire Retardant Soybean-Oil Based Copolymers Containing Silicon or Boron: Comparison of Additive and Reactive Approaches. Polymer Degradation and Stability. 95, Pages 1269-1274. 
9 Zilbermann, J., Hull, T. R., Price, D., Milnes, G. J., and Keen, F., (2000) Flame retardancy of some ethylenevinyl acetate copolymer-based formulations, Fire and Materials, 24, pages 159-164.

10 Hull, T.R., Price, D., Liu, Y., Wills, C.L., and Brady, J., (2003) An Investigation into the Decomposition and Burning Behaviour of EVA Nanocomposite Materials, Polymer Degradation and Stability 82, pages 365-371.

11 Hull, T.R., Stec, A. A., Nazare, S., (2009) Fire Retardant Effects of Polymer Nanocomposites, Journal of Nanoscience and Nanotechnology 9, pages 4478-4486.

12 Wang, D-Y., Wang, J-S. Ge, X-G. Wang, Y-Z., Stec, A. A., and Hull, T. R., (2009) Preparation and characterisation of a novel flame retarded PET/ $\alpha$ zirconium phosphate nanocomposite ( $\alpha$-ZrP), Polymer Degradation and Stability 94, Pages 544-549.

13 Staggs, J. E. J., (1998), A Theory for Quasi-Steady Single-Step Thermal Degradation of Polymers. Fire and Materials. 22(3), pages 109-118.

14 Zhang, J., Delichatsios, M. A., and Bourbigot, S., (2009), Experimental and Numerical Study of the Effects of Nanoparticles on Pyrolysis of Polyamide 6 (PA6) Nanocomposite in the Cone Calorimeter. Combustion and Flame. 156(11), pages 2056-2062.

15 Jia, F., Galea, E. R., and Patel, M. K., (1999), The Numerical Simulation of the Noncharring Pyrolysis Process and Fire Development Within a Compartment. Applied Mathematical Modelling. 23(11), pages 587-607.

16 Stoliarov, S. I., and Lyon, R. E., (2008), Thermo-Kinetic Model of Burning. Federal Aviation Administration Technical Note DOT/FAA/AR-TN-08/17.

17 Stoliarov, S. I., Crowley, S., Lyon, R. E., and Linteris, G. T., (2009), Prediction of the Burning Rates of NonCharring Polymers. Combustion and Flame. 156, pages 1068-1083

18 Stoliarov, S. I., Safronava, N., and Lyon, R. E., (2009), The Effect of Variation in Polymer Properties on the Rate of Burning. Fire and Materials. 33(6), pages 257-271

19 Rahatekar, S. S., Zammarano, M., Matko, S., Koziol, K. K., Windle, M. H., Kashiwagi, T., and Gilman, J. W., (2010), Effect of Carbon Nanotubes and Montmorillonite on the Flammability of Epoxy Nanocomposites. Polymer Degradation and Stability. doi:10.1016/j.polymdegradstab.2010.01.003

20 Quintiere, J. G., (1997), Principles of Fire Behaviour. Delmar. Albany, NY.

21 Drysdale, D., (1999), An Introduction to Fire Dynamics. 2nd Edition. John Wiley \& Sons, Chichester.

22 Lyon, R. E., Safronava, N., and Stoliarov, S. I., (2010), The Role of Thermal Decomposition Kinetics in the Burning of Polymers. Proceedings of the 12th International Conference on Fire Science and Engineering (INTERFLAM), University of Nottingham, UK, July $5-7$ th.

23 Lyon, R. E., and Walters, R., (2002), A Microscale Combustion Calorimeter. US Department of Transport. Report Number: DOT/FAA/AR-01/117. Federal Aviation Administration.

24 Lyon, R. E., and Quintiere, J. G., (2007), Criteria for Piloted Ignition of Combustible Solids. Combustion and Flame. 151, pages 551-559.

25 Walters, R. N., Hackett, S. M., and Lyon, R. E., (2000), Heats of Combustion of High Temperature Polymers. Fire and Materials. 24, pages 245-252. 